\title{
Relationship Between Sleep Duration and Stroke History in Middle-Aged and Elderly in Guiyang: A Cross-Sectional Survey
}

\author{
Li Liu', Jingyuan Yang', Junhua Wang', Meng Nie², Ziyun Wang', Han Guan', Jin Hu', Feng Hong' \\ 'School of Public Health, The Key Laboratory of Environmental Pollution Monitoring and Disease Control, Ministry of Education, Guizhou Medical \\ University, Guiyang, Guizhou, People's Republic of China; ${ }^{2}$ School of Public Health, Guizhou Medical University, Guiyang, Guizhou, People's Republic \\ of China
}

Correspondence: Feng Hong, School of Public Health, The Key Laboratory of Environmental Pollution Monitoring and Disease Control, Ministry of Education, Guizhou Medical University, Guiyang, Guizhou, People's Republic of China, Tel +86-13984I8098I, Email 64048857@qq.com

Background: With over 2 million new cases annually, stroke is associated with the higher amount of disability-adjusted life-years lost than any other disease in China; however, the relationship between sleep time and stroke has not been concluded yet. Aim of this study was to analyze the relationship between sleep duration and stroke history in middle-aged and elderly people in Guiyang, China.

Methods: This study was a cross-sectional survey carried out in 40-99-years-old permanent residents of Guiyang. Yunyan, Wudang, and Baiyun districts and Xiuwen County were selected by stratified multilevel sampling for a face-to-face survey. Demographics, history of stroke, and self-reported sleep behavior data were collected, and multivariable logistic regression models were used to gradually adjust possible confounding factors.

Results: A total of 5065 participants were included, of them $126(2.5 \%)$ had a history of stroke. Short sleep $(<7 \mathrm{~h})$ was observed in $11.0 \%$, sufficient sleep (7-9 h) in 69.4\%, and long sleep ( $>9 \mathrm{~h}$ ) in 19.6\%. Sleep duration and stroke prevalence showed a U-shaped distribution. When taking the sleep duration of $7-9 \mathrm{~h}$ as a reference, sleep duration $>9 \mathrm{~h}$ was associated with stroke (all $\mathrm{P}<0.05)$ in the univariable model $(\mathrm{OR}=2.68,95 \% \mathrm{CI}: 1.83-3.93)$ and in the multivariable models $1(\mathrm{OR}=2.35,95 \% \mathrm{CI}: 1.59-3.47), 2(\mathrm{OR}=2.27$, 95\% CI: 1.53-3.37), $3(\mathrm{OR}=2.25,95 \% \mathrm{CI}: 1.51-3.33)$, and $4(\mathrm{OR}=2.11,95 \% \mathrm{CI}: 1.39-3.19)$. There were no significant differences between the $<7$ and $7-9 \mathrm{~h}$ groups $(\mathrm{P}>0.05)$.

Conclusion: Thus, long sleep duration $(>9 \mathrm{~h})$ is independently associated with history of stroke in middle-aged and elderly people in Guiyang.

Keywords: stroke, sleep duration, prevalence, middle-aged, elderly, China

\section{Introduction}

Stroke is a cerebrovascular disease that rapidly leads to localized or diffuse brain dysfunction due to acute cerebral circulation disorder. ${ }^{1}$ Stroke features a high mortality rate (about 5.5 million each year) and high morbidity rate, as well as long-term disability in up to $50 \%$ of survivors. ${ }^{2,3}$ The incidence of stroke in China is 298 per 100,000 person-years in rural areas and 204 per 100,000 person-years in urban areas, ${ }^{4}$ with geographic variations across the country ${ }^{5}$ and the incidence is increasing over time. ${ }^{6}$ Stroke is, therefore, a significant public health burden. The risk factors for stroke include among others a history of transient ischemic attacks, smoking, metabolic syndrome, hypertension, heavy alcohol use, diabetes mellitus type 2, high cholesterol levels, carotid artery stenosis, obesity, and poor physical status. ${ }^{7,8}$

Sleep duration and quality are able to affect not only the quality of life but also physical health. ${ }^{9,10}$ Previously, sleep duration was reported to be associated with hypertension, diabetes, and other diseases, ${ }^{9}$ and frequent snoring during sleep has been associated with the risk of stroke in various populations. ${ }^{10-12}$ Furthermore, recent studies showed that both short and long duration of sleep are predictors of cardiovascular outcomes and relationship between sleep duration and the risk of stroke follows a J-shaped curve, as stroke may follow a shift in sleep patterns, and sleep patterns in turn might be 
affected by a history of stroke and related changes in everyday life. ${ }^{13,14}$ When considering a normal sleep duration of 7 $\mathrm{h}$ as a reference (9), sleep duration $<7 \mathrm{~h}$ will increase the risk of stroke by $7 \%$ for every $1 \mathrm{~h}$ of shorter sleep, and $>7 \mathrm{~h}$ will increase the risk of stroke by $17 \%$ for every $1 \mathrm{~h}$ of sleep duration $>7 \mathrm{~h} .{ }^{14}$

Nevertheless, considering the wide variation in the incidence of stroke among different regions in China, it is possible that the relationship between sleep duration and the risk of stroke also varies considerably. ${ }^{15,16}$ Because of the low prevalence of stroke in the community, it was hypothesized that in Guiyang, a city in southwest China, currently in the process of gradual urbanization with relatively high level of medical services, sleep time may differ along with the relationship to stroke caused by it. Epidemiological studies with sufficiently large population samples can provide reliable evidence to answer the necessary research questions discussed above.

Therefore, the purpose of this study was to investigate the relationship between sleep duration and history of stroke in the middle-aged and elderly people in Guiyang through a survey of more than 10,000 residents in Guiyang. The research results can provide a reference for the prevention and control of stroke.

\section{Materials and Methods}

\section{Study Design and Participants}

The survey adopted stratified and multilevel sampling methods and was held from July 2017 to August 2017. According to the geographical location, Guiyang city was divided into three types of regions, and in each region, a district was randomly selected according to the random number table method, and then 1 township (town or community) was randomly selected from each district. In the final selected area, the survey was conducted with the family as the unit, and all middle-aged and elderly members were included in this study as the subjects of the survey. The inclusion criteria were 1) voluntary participation; 2) $>40$ years of age, and 3) During investigation, local residents who have left Guiyang for $<12$ months or migrant residents who have lived for $>6$ months in Guiyang in the past 12 months. Those potential participants who were unable to finish the survey after three attempts including contacting relatives were excluded. The study was conducted in accordance with the Declaration of Helsinki and approved by the ethics committee of Drug Clinical Trial of Affiliated Hospital of Guizhou Medical University, and all participants signed the informed consent form.

\section{Survey Method}

The questionnaire of the 2017 Guiyang Residents Disease Spectrum Survey was adopted, with the household as a unit, and a face-to-face questionnaire survey was conducted by all residents who met the eligibility criteria in the household. In principle, the questionnaire had to be answered face to face. For those who could not answer the questionnaire due to physical, mental, intellectual, and age factors, their families answered the questionnaire on their behalf. The survey contents included general situation (sex, age, nationality, education, marital status, and annual family income), stroke history, sleep behavior (including sleep duration and sleep quality), and lifestyle behaviors (smoking, drinking, and exercise frequency).

\section{Definition of Relevant Indicators and Grouping}

For participants who acknowledged the history of stroke, diagnosis was confirmed by contacting a local hospital. Sleep duration was calculated from "sleep duration and getting up time in the past month" questionnaire section, and the participants were divided into $<7,7-9$, and $>9 \mathrm{~h}$. Referring to the sleep duration standard, ${ }^{17}<7 \mathrm{~h}$ was regarded as short sleep duration, 7-9 h was considered as average sleep duration, and $>9 \mathrm{~h}$ was considered as long sleep duration. Sleep quality was obtained from the "self-evaluation of night sleep quality in the past month" questionnaire section. In this study, sleep quality was self-reported by participants using a five-point Likert scale as "very good, good, fair, poor, and very poor" However, the number of "very good" and "very poor" cases was small, so we combined the data for the statistical assessment (very good was considered as good, and very poor was considered as poor). Thus, sleep quality, as well as general health status, were divided into "good" (including "very good" and "good"), average, and poor (including "very poor" and "poor"). Hypertension, diabetes, and coronary heart disease were reported by the participants, according 
to a previously known diagnosis. Overweight and obesity were evaluated based on the body mass index (BMI, $\left.\mathrm{kg} / \mathrm{m}^{2}\right)$. In this study, the Chinese Adult Weight Determination Standard was adopted to classify overweight and obesity: ${ }^{18}$ BMI < 18.5 was lean, $18.5 \leq$ BMI $<24.0$ was normal, $24.0 \leq$ BMI $<28.0$ was overweight, and BMI $\geq 28.0$ was obesity. Exercising was defined as physical activity specifically aimed at improving health or fitness (excluding walking to/from work or other everyday activities) and according to frequency exercising was divided into $0-3,4-5$, and 6-7 days/week.

\section{Calculation of Sample Size}

The sample size was calculated using the following equation ${ }^{19} n=\frac{Z_{1-\alpha / 2^{2}} \times p q}{d^{2}}$

The adopted prevalence of stroke was $5 \%,{ }^{20,21}$ and the allowable error was $d=0.2 p, \alpha$ Take 0.05 and the calculated sample size is 1900 . Considering the design effect deff $=2{ }^{22}$ the total sample size $n=n \times$ Deff $=1900 \times 2=3800$; Considering the $20 \%$ loss of follow-up rate, at least 4750 cases should be included in this study.

\section{Statistical Method}

EpiData 3.1 (Centers for Disease Control, Atlanta, GA, USA) was used to establish the database. All data were doubleentered and verified by comparison of the independent two entries. SPSS 25.0 (IBM Corp, Armonk, NY, USA) was used for statistical analysis. The data are described as means \pm standard deviations and $n(\%)$. The distribution of sleep duration and the prevalence of stroke according to different characteristics were tested using the chi-square test. The relationship between sleep duration and stroke was analyzed by a two-classification logistic regression model. First, univariable logistic regression analysis was carried out with sleep duration as the independent variable and stroke prevalence as the dependent variable. Then, the possible confounding factors were gradually added using a multivariable logistic regression analysis (Supplementary Table S1): Model 1: adjusted for sex and age; Model 2: On the basis of Model 1, adjusted for education, occupation, marital status and migrant workers; Model 3: on the basis of Model 2, adjusted for smoking, drinking, and sitting or leaning time every day; and Model 4: on the basis of Model 3, further adjusted for health status, sleep quality, hypertension, diabetes, and coronary heart disease. GraphPad Prism 8.4.2 (GraphPad Software Inc., San Diego, CA, USA) was used to draw the forest map of the results of the multivariate analysis. Two-sided P-values $<0.05$ were considered statistically significant.

\section{Results}

\section{Characteristics of the Participants}

A total of 5065 participants were included in the analysis, aged between 40 and 99, with a Median age of 57.5 (48.8, 67.9) years. Among them, 2327 (45.9\%) were men, and 2738 (54.1\%) were women. By profession, participants were mainly farmers $(26.7 \%)$ and unemployed/out of work (24.5\%), 53.5\% of them had a primary school education or below, $81.7 \%$ were married, $46.9 \%(\mathrm{n}=2373)$ felt that their health status was "good" and $17.8 \%(902)$ felt that their health status was "poor", and 2816 (55.6\%) suffered from chronic diseases (Table 1).

\section{Distribution of Self-Reported Sleep Duration with Different Characteristics}

Among the 5065 subjects, 555 (11.0\%) had slept $<7$ h, 3516 (69.4\%) slept 7-9 h, and 994 (19.6\%) slept $>9$ h. People of different ages, education, occupation, marital status, health status, sleep quality, regular three meals, dietary pattern, smoking, and drinking had different sleep durations (all $\mathrm{P}<0.05$ ) (Table 1). With increasing age, the proportion of people who slept for 7-9 h gradually decreased $\left(\mathrm{P}_{\text {trend }}<0.001\right)$ (Table 1$)$.

\section{Prevalence of Stroke}

A total of 126 middle-aged and elderly people suffered from a stroke in this survey, with a prevalence of $2.5 \%$, including 55 men (prevalence of 2.4\%) and 71 women (prevalence of 2.6\%). The prevalence of stroke was the lowest $(1.8 \%)$ among the subjects with 7-9 h of sleep duration, while the prevalence of stroke among the subjects with $<7$ and $>9 \mathrm{~h}$ of sleep duration increased continuously and showed a $U$ shape distribution. The prevalence of stroke among the subjects with long sleep duration $(>9 \mathrm{~h})$ was higher than that of the subjects with short sleep duration $(<7 \mathrm{~h})$. With increasing age, 
Table I Characteristics of 5065 Middle-Aged and Elderly People in Guiyang City in 2017 According to Sleep Duration

\begin{tabular}{|c|c|c|c|c|c|c|c|c|}
\hline \multirow[t]{2}{*}{ Item } & \multirow[t]{2}{*}{ Grouping } & \multirow[t]{2}{*}{$\mathbf{n}$} & \multirow[t]{2}{*}{$\%$} & \multicolumn{3}{|c|}{ Sleep Duration } & \multirow[t]{2}{*}{$\chi^{2}$} & \multirow[t]{2}{*}{$\mathbf{P}$} \\
\hline & & & & $<7 \mathrm{~h}$ & $7-9 \mathrm{~h}$ & $>9 \mathrm{~h}$ & & \\
\hline \multirow[t]{2}{*}{ Gender } & Male & 2327 & 45.9 & 277 (II.9) & 1600 (68.8) & 450 (19.3) & 3.967 & 0.138 \\
\hline & Female & 2738 & 54.1 & $278(10.2)$ & $1916(70.0)$ & $544(19.3)$ & & \\
\hline \multirow[t]{5}{*}{ Age } & $40 \sim$ & 1453 & 28.7 & 155 (10.7) & 1037 (7I.4) & $261(18.0)$ & 70.380 & $<0.001$ \\
\hline & $50 \sim$ & 1382 & 27.3 & $179(13.0)$ & $975(70.5)$ & $228(16.5)$ & & \\
\hline & $60 \sim$ & 1154 & 22.8 & 137 (II.9) & $796(69.0)$ & $221(19.2)$ & & \\
\hline & $70 \sim$ & 768 & 15.2 & $68(8.9)$ & $521(67.8)$ & $179(23.3)$ & & \\
\hline & $\geq 80$ & 308 & 6.1 & $16(5.2)$ & $187(60.7)$ & 105 & & \\
\hline \multirow[t]{2}{*}{ Marital Status } & Married & 4140 & 81.7 & $450(10.9)$ & 2918 (70.5) & $772(18.6)$ & 14.906 & 0.001 \\
\hline & Others & 925 & 18.3 & 105 (II.4) & $598(64.6)$ & $222(24.0)$ & & \\
\hline \multirow[t]{4}{*}{ Body mass index } & Lean & 2716 & 53.6 & $29(10.8)$ & $176(65.4)$ & $64(23.8)$ & 6.449 & 0.375 \\
\hline & Normal & 269 & 5.3 & $286(10.5)$ & $1883(69.3)$ & $547(20.1)$ & & \\
\hline & Overweight & 1538 & 30.4 & $174(|| .3)$ & 1080 (70.2) & $284(18.5)$ & & \\
\hline & Obese & 542 & 10.7 & $66(12.2)$ & 377 (69.9) & $99(18.3)$ & & \\
\hline Chronic diseases & & 2816 & 55.6 & 324 (II.5) & $1930(68.5)$ & $562(20.0)$ & 2.805 & 0.246 \\
\hline Hypertension & & 1092 & 21.6 & $110(10.1)$ & $742(67.9)$ & $240(22.0)$ & 5.354 & 0.069 \\
\hline Diabetes & & 268 & 5.3 & $29(10.8)$ & $179(66.8)$ & $60(22.4)$ & 1.387 & 0.500 \\
\hline $\mathrm{CHD}$ & & 119 & 2.3 & $13(10.9)$ & $79(66.4)$ & $27(22.7)$ & 0.744 & 0.689 \\
\hline Stroke & & 126 & 2.5 & 15 (II.9) & $64(50.8)$ & $47(37.3)$ & 27.136 & $<0.001$ \\
\hline \multirow[t]{3}{*}{ Smoking } & Never & 2996 & 59.2 & $292(9.7)$ & $2114(70.6)$ & 590 (19.7) & 14.412 & 0.006 \\
\hline & Current & 1702 & 33.6 & $226(13.3)$ & II 47 (67.4) & $329(19.3)$ & & \\
\hline & Previous & 367 & 7.2 & $37(10.1)$ & $255(69.5)$ & $75(20.4)$ & & \\
\hline \multirow[t]{3}{*}{ Drinking alcohol } & Never & 2996 & 59.2 & $301(10.0)$ & $2080(69.4)$ & $615(20.5)$ & 16.091 & 0.003 \\
\hline & Current & 1608 & 31.7 & $201(12.5)$ & II 33 (70.5) & $274(17.0)$ & & \\
\hline & Previous & 461 & 9.1 & 53 (II.5) & $303(65.7)$ & $105(22.8)$ & & \\
\hline \multirow[t]{3}{*}{ Sleep quality } & Good & 3038 & 60.0 & $286(9.4)$ & 2154 (70.9) & 598 (19.7) & 43.090 & $<0.001$ \\
\hline & General & 1030 & 20.3 & $103(10.0)$ & $728(70.7)$ & $199(19.3)$ & & \\
\hline & Poor & 997 & 19.7 & $166(16.6)$ & $634(63.6)$ & $197(19.8)$ & & \\
\hline \multirow[t]{3}{*}{ Exercise frequency (day/week) } & $0-3$ & 3704 & 73.1 & $410(11.1)$ & $2509(67.7)$ & $785(2 \mid .2)$ & 23.059 & $<0.001$ \\
\hline & $4-5$ & 229 & 4.5 & $25(10.9)$ & $169(73.8)$ & $35(15.3)$ & & \\
\hline & $6-7$ & 1132 & 22.3 & $120(10.6)$ & $838(74.0)$ & $174(15.4)$ & & \\
\hline
\end{tabular}

Abbreviation: CHD, coronary heart disease.

the prevalence of stroke gradually increased $\left(\mathrm{P}_{\text {trend }}<0.001\right)$. The prevalence of stroke among middle-aged and elderly people with different occupations, education, marital status, health status, chronic disease, sleep quality, smoking, sitting or leaning time and drinking status was significantly different (all $\mathrm{P}<0.05$ ) (Table 2).

\section{Relationship Between Self-Reported Sleep Duration and Stroke History}

The results of the univariable and multivariable logistic regression analysis showed that when taking the sleep duration of 7-9 $\mathrm{h}$ as reference, sleep duration $>9 \mathrm{~h}$ was associated with reported history of stroke (all $\mathrm{P}<0.05)$ in the univariable model $(\mathrm{OR}=2.68$, 95\% CI: 1.83-3.93) and in the multivariable model $1(\mathrm{OR}=2.35,95 \% \mathrm{CI}: 1.59-3.47)$, model 2 ( $\mathrm{OR}=2.27,95 \% \mathrm{CI}: 1.53-3.37)$, model $3(\mathrm{OR}=2.25,95 \% \mathrm{CI}: 1.51-3.33)$, and model $4(\mathrm{OR}=2.11,95 \% \mathrm{CI}: 1.39-3.19)$. There were no significant differences between the $<7$ and $7-9 \mathrm{~h}$ groups $(\mathrm{P}>0.05)$ (Table 3 and Figures 1 and Figures 2$).$

\section{Discussion}

Sleep duration is associated with the risk of stroke, ${ }^{13,14}$ but the incidence of stroke varies considerably in different countries and often even within one country. ${ }^{2-5}$ Therefore, the relationship between sleep duration and stroke could also vary. The relationship between sleep time and stroke has not been concluded yet in China. This study aimed to study the relationship between selfreported sleep duration and history of stroke in middle-aged and elderly people in Guiyang, China. 
Table 2 Prevalence of Stroke in 5065 Middle-Aged and Elderly People in Guiyang City in 2017

\begin{tabular}{|c|c|c|c|c|c|}
\hline Item & Grouping & With Stroke & Without Stroke & $\chi^{2} / Z$ & $\mathbf{P}$ \\
\hline \multirow[t]{2}{*}{ Gender } & Male & $55(2.4)$ & $2272(97.6)$ & 0.273 & 0.601 \\
\hline & Female & $71(2.6)$ & $2667(97.4)$ & & \\
\hline \multirow[t]{5}{*}{ Age } & $40 \sim$ & $6(0.4)$ & I447 (99.6) & 74.885 & $<0.001$ \\
\hline & $50 \sim$ & $22(1.6)$ & $1360(98.4)$ & & \\
\hline & $60 \sim$ & $4 \mid(3.6)$ & $1113(96.4)$ & & \\
\hline & $70 \sim$ & $36(4.7)$ & $732(95.3)$ & & \\
\hline & $\geq 80$ & $21(6.8)$ & $287(93.2)$ & & \\
\hline \multirow[t]{2}{*}{ Marital Status } & Married & $94(2.3)$ & $4046(97.7)$ & 4.406 & 0.036 \\
\hline & Others & $32(3.5)$ & $893(96.5)$ & & \\
\hline \multirow[t]{3}{*}{ Health status } & Good & $24(1.0)$ & $2349(99.0)$ & 154.659 & $<0.001$ \\
\hline & General & $27(1.5)$ & $1763(98.5)$ & & \\
\hline & Poor & $75(8.3)$ & $827(91.7)$ & & \\
\hline Chronic diseases & & $112(4.0)$ & $2704(96.0)$ & 58.012 & $<0.001$ \\
\hline \multirow[t]{3}{*}{ Sleep duration } & $<7 \mathrm{~h}$ & $15(2.7)$ & $540(97.6)$ & 27.136 & $<0.001$ \\
\hline & $7-9 \mathrm{~h}$ & $64(1.8)$ & 3452 (98.2) & & \\
\hline & $>9 \mathrm{~h}$ & $47(4.7)$ & $947(95.3)$ & & \\
\hline \multirow[t]{3}{*}{ Sleep quality } & Good & $50(1.6)$ & $2988(98.4)$ & 26.901 & $<0.001$ \\
\hline & General & $31(3.0)$ & $999(97.0)$ & & \\
\hline & Poor & $45(4.5)$ & $952(95.5)$ & & \\
\hline \multirow[t]{3}{*}{ Smoking } & Never & $78(2.6)$ & $2918(97.4)$ & 6.149 & 0.046 \\
\hline & Current & $33(1.9)$ & $1669(98.1)$ & & \\
\hline & Previous & $15(4.1)$ & 352 (95.9) & & \\
\hline \multirow[t]{3}{*}{ Drinking alcohol } & Never & $88(2.9)$ & $2908(97.1)$ & 18.877 & $<0.001$ \\
\hline & Current & $19(1.2)$ & $1589(98.8)$ & & \\
\hline & Previous & $19(4.1)$ & $442(95.9)$ & & \\
\hline \multirow[t]{3}{*}{ Exercise frequency (day/week) } & $0-3$ & $86(2.3)$ & $3618(97.7)$ & 1.678 & 0.432 \\
\hline & $4-5$ & $6(2.6)$ & $223(97.4)$ & & \\
\hline & $6-7$ & $34(3.0)$ & $1098(96.0)$ & & \\
\hline \multirow[t]{4}{*}{ BMI } & Lean & $64(2.4)$ & $2652(97.6)$ & 2.348 & 0.503 \\
\hline & Normal & $7(2.6)$ & $262(97.6)$ & & \\
\hline & Overweight & $45(2.9)$ & $1493(97.1)$ & & \\
\hline & Obese & $10(1.8)$ & $532(98.2)$ & & \\
\hline Hypertension & & $88(8.1)$ & $1004(91.9)$ & 178.111 & $<0.001$ \\
\hline Diabetes & & $20(7.5)$ & $248(92.5)$ & 28.873 & $<0.001$ \\
\hline CHD & & $12(10.1)$ & $107(89.9)$ & 28.989 & $<0.001$ \\
\hline Sitting or leaning time & & $5.00(3.00,7.00)$ & $4.50(3.00,6.00)$ & -2.202 & 0.028 \\
\hline
\end{tabular}

Abbreviations: BMI, body mass index $\left(\mathrm{kg} / \mathrm{m}^{2}\right)$; $\mathrm{CHD}$, coronary heart disease.

Based on the conducted population-based survey and research, with a large sample size and strong statistical power, the relationship between sleeping habits and stroke was explored for the community populations in Guiyang City. Due to the relatively high level of medical services in Guiyang City compared to cities around, the overall incidence of stroke was low, but after controlling the possible confounding risk factors, the independent association between long sleep duration $(>9 \mathrm{~h}$ ) and history of stroke was still identified, which provides a scientific basis for future in-depth research on the impact of sleep on stroke and intervention studies.

In this study, the prevalence of stroke was $2.5 \%$ among middle-aged and elderly people aged $\geq 40$ years old in Guiyang, ${ }^{5,20,21,23} 2.4 \%$ for men and $2.6 \%$ for women, without significant difference, gradually increased with age. Found prevalence values are slightly lower than reported in neighboring provinces, which contributes to the epidemiological study of stroke distribution over China. ${ }^{5,20,21,23}$ Differences might be partly explained by a higher level of medical services in Guiyang City compared to cities around; in addition, the prevalence of stroke in individuals with 
Table 3 Correlation Between Sleep Duration and Stroke in Middle-Aged and Elderly People in Guiyang City, OR $(95 \% \mathrm{Cl})$

\begin{tabular}{|l|l|l|l|l|}
\hline \multirow{2}{*}{ Item } & & Sleep Duration & \multicolumn{2}{l|}{} \\
\cline { 3 - 5 } & & $<7$ h & 7-9 h & $>9$ h \\
\hline Univariable model & - & $1.498(0.848-2.648)$ & 1 & $2.677(1.825-3.927)^{*}$ \\
Multivariable model & $\mathrm{I}$ & $1.600(0.900-2.843)$ & $\mathrm{I}$ & $2.346(1.589-3.465)^{*}$ \\
& 2 & $1.718(0.963-3.065)$ & $\mathrm{I}$ & $2.272(1.533-3.367)^{*}$ \\
& 3 & $1.700(0.952-3.036)$ & $\mathrm{I}$ & $2.245(1.514-3.331)^{*}$ \\
& 4 & $1.673(0.911-3.071)$ & $\mathrm{I}$ & $2.107(1.391-3.190)^{*}$ \\
\hline
\end{tabular}

Notes: The univariable factor model includes sleep duration only. Model I: sleep duration, gender, and age. Model 2: Model I, educational level, occupation, marital status, and migrant workers. Model 3: Model 2, smoking, drinking, and sitting or leaning time every day. Model 4: Model 3, health status, sleep quality, hypertension, diabetes, and coronary heart disease. $* \mathrm{P}<0.05$.

hypertension, diabetes, and coronary heart disease was $8.1 \%, 7.5 \%$, and $10.1 \%$, respectively, which was significantly higher than in individuals without these diseases, also in line with previous studies. ${ }^{5,7,8,20,21,23}$

Of the 5065 middle-aged and elderly participants in Guiyang, most (69.4\%) had reported normal sleep duration (7-9 h), 11\% had short sleep duration ( $<7 \mathrm{~h}$ ), while 19.6\% reported long sleep duration ( $>9 \mathrm{~h})$. Age, education, occupation, marital status, health status, sleep quality, smoking status, and drinking status were all associated with sleep duration. Moreover, the worse the sleep quality, the greater the proportion of people who have short sleep duration, as observed by previous studies, ${ }^{16}$ confirming that quality ${ }^{24}$ of sleep appears to depend on its quantity among other factors. ${ }^{24}$

This study showed that the prevalence of stroke in middle-aged and elderly people with different sleep duration was different. The prevalence of stroke in people with normal sleep duration $(7-9 \mathrm{~h})$ was the lowest, at $1.8 \%$, while in people with long sleep duration ( $>9 \mathrm{~h})$ it was equal to $4.7 \%$, still higher than that in people with short sleep duration $(<7 \mathrm{~h})$ (2.7\%): so called a "U" distribution between sleep duration and stroke. This relationship was still observed after adjusting for the other risk factors of stroke, being in line with previous studies. ${ }^{11,13,14,16,25,26}$

Various reasons might explain the relationship between long sleep and stroke. As our study was retrospective by the nature, it is possible that in some of the participants sleep patterns have shifted to the longer sleep duration even after the stroke. However, previous studies have reported that long sleep is associated with elevated inflammatory markers, ${ }^{27,28}$ and inflammation is involved in the pathogenesis of stroke. ${ }^{7,8,29}$ Long sleep is also associated with high blood lipid levels, ${ }^{30,31}$ which directly contribute to atherogenesis. In addition, the elevated prevalence of metabolic syndrome, ${ }^{32}$ carotid artery stenosis, ${ }^{33}$ and white matter hyperintensities $^{34,35}$ is observed in people with long sleep duration. Indirect associations could be found between long sleep and a more sedentary life, ${ }^{36,37}$ depression, sleep apnea, and lower socioeconomic status, ${ }^{12,38,39}$ which are all risk factors for stroke. ${ }^{7,8}$ The research hypothesis implied that in Guiyang, a city in southwest China, the process of gradual urbanization led to the significant change of lifestyle in elderly, and thus sleep time may differ along with the relationship to stroke caused by it. With the continuous development of China's economy, many cities are in the process of urbanization right now, and the change of lifestyle will be relevant to other developing regions as a point of comparison. In addition, the correlation degree is relatively strong; thus, it could be applied to the situation of younger people, in which sleep time shortens for other reasons, so in the future, it might lead to

\begin{tabular}{|c|c|c|c|c|}
\hline Variables & & OR & $(95 \% \mathrm{Cl})$ & P Value \\
\hline Sleep duration $(>9 \mathrm{~h})$ & $\longrightarrow$ & 2.677 & (1.825-3.927) & $<0.001$ \\
\hline Sleep duration $(<7 \mathrm{~h})$ & - & 1.498 & $(0.848-2.648)$ & 0.164 \\
\hline
\end{tabular}

Figure I Univariable model for the association between sleep duration and the risk of stroke. Single factor model. 


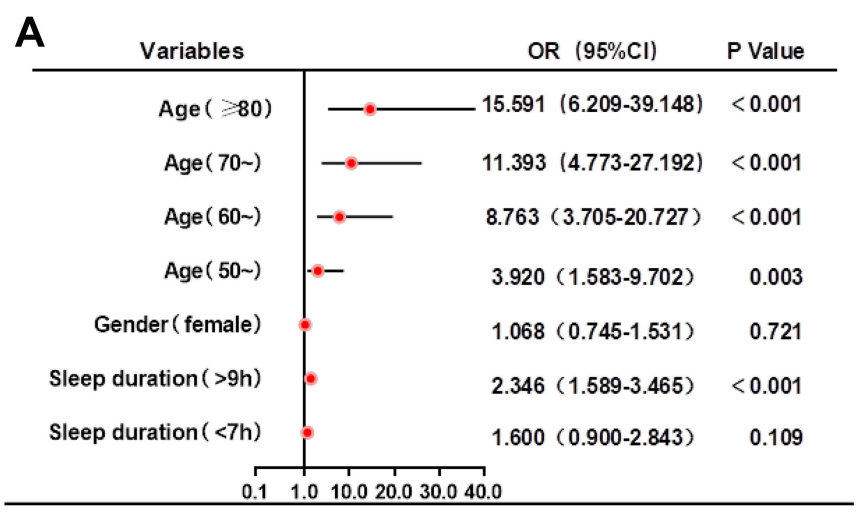

B

B

B

Variables

Marital Status (Others)

College or above

High school/Technical secondary school

Junior middle school

Primary school

Other occupations

Workers

Retirees

Private business owner/ Self-employed person
Teachers /Civil servants/

Institutions

Migrant workers(no)

Age $(\geqslant 80$ )

Age (70 )

Age (60 )

Age (50 )

Sleep duration ( $>9 h$ )

Sleep duration $(<7 \mathrm{~h})$

\begin{tabular}{|cc} 
OR $(95 \% \mathrm{Cl})$ & P Value \\
\hline $0.810(0.524-1.254)$ & 0.345 \\
$0.286(0.066-1.239)$ & 0.094 \\
$1.093(0.551-2.169)$ & 0.798
\end{tabular}

$0.976(0.571-1.670) \quad 0.930$

$1.300(0.811-2.084) \quad 0.275$

$0.469(0.160-1.370) \quad 0.166$

$0.000(0.000-0.000) \quad 0.994$

$0.672(0.418-1.080) \quad 0.101$

0.314(0.095-1.043) $\quad 0.059$

$0.000(0.000-0.000) \quad 0.996$

$0.418(0.253-0.692) \quad 0.001$

3.965(0.539-29.141) $\quad 0.176$

9.948(3.644-27.152) $<0.001$

7.353(2.893-18.691) $<0.001$

6.096(2.471-15.039) <0.001

3.192(1.273-8.004) $\quad 0.013$

2.272(1.533-3.367) $<0.001$

1.718(0.963-3.065) $\quad 0.067$

$0.11 .0 \quad 10.020 .030 .0$

C

\begin{tabular}{|c|c|c|c|}
\hline Variables & & OR $(95 \% \mathrm{Cl})$ & $\mathrm{P}$ Value \\
\hline Sitting or leaning time & & $1.049(0.985-1.118)$ & 0.138 \\
\hline Used to drink & & $0.948(0.523-1.720)$ & 0.861 \\
\hline Still drink & & $0.465(0.266-0.814)$ & 0.007 \\
\hline Used to smoke & & $1.570(0.815-3.028)$ & 0.178 \\
\hline Still smoke & & $1.127(0.700-1.814)$ & 0.623 \\
\hline Other occupations & & $0.428(0.147-1.245)$ & 0.119 \\
\hline Workers & & $0.000(0.000-0.000)$ & 0.994 \\
\hline Retirees & & $0.649(0.421-1.000)$ & 0.050 \\
\hline $\begin{array}{r}\text { Private business owner } \\
\text { /Self-employed person } \\
\text { Teachers /Civil servants } \\
\text { /Institutions }\end{array}$ & & $\begin{array}{l}0.319(0.096-1.057) \\
0.000(0.000-0.000)\end{array}$ & $\begin{array}{l}0.062 \\
0.996\end{array}$ \\
\hline Famers & & $0.473(0.287-0.779)$ & 0.003 \\
\hline Age $(\geqslant 80)$ & $-\div$ & $8.007(3.021-21.219)$ & $<0.001$ \\
\hline Age ( 70 ) & $-*-$ & $6.885(2.753-17.217)$ & $<0.001$ \\
\hline Age (60 ) & $-\infty$ & $6.057(2.468-14.864)$ & $<0.001$ \\
\hline $\operatorname{Age}(50 \sim)$ & - & $3.235(1.290-8.113)$ & 0.012 \\
\hline Sleep duration ( $>9 h$ ) & 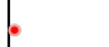 & $2.245(1.514-3.331)$ & $<0.001$ \\
\hline Sleep duration $(<7 \mathrm{~h})$ & t. & $1.700(0.952-3.036)$ & 0.073 \\
\hline 0.1 & $1.0 \quad 10.020$. & .030 .0 & \\
\hline
\end{tabular}

\begin{tabular}{|c|c|c|c|}
\hline Variables & & OR( $(95 \% \mathrm{Cl})$ & $P$ Value \\
\hline Coronary heart disease & $-\infty$ & $1.819(0.908-3.643)$ & 0.091 \\
\hline Diabetes & + & $1.429(0.824-2.478)$ & 0.203 \\
\hline Hyertension & $-\div$ & 4.902(3.226-7.448) & $<0.001$ \\
\hline Sleep quality ( poor) & 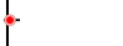 & $1.163(0.735-1.841)$ & 0.519 \\
\hline Sleep quality (general) & e- & $1.545(0.949-2.514)$ & 0.080 \\
\hline Health status ( poor) & $-\div$ & $3.850(2.305-6.431)$ & $<0.001$ \\
\hline Health status ( general) & & $0.840(0.473-1.493)$ & 0.552 \\
\hline Used to drink & - & $1.234(0.715-2.131)$ & 0.449 \\
\hline Still drink & & $0.697(0.411-1.183)$ & 0.181 \\
\hline Other occupations & - & $0.773(0.258-2.315)$ & 0.645 \\
\hline Workers & & $0.000(0.000-0.000)$ & 0.995 \\
\hline Retirees & & $0.832(0.527-1.315)$ & 0.431 \\
\hline $\begin{array}{l}\text { Private business owner/ } \\
\text { Self-employed person }\end{array}$ & & $0.491(0.145-1.663)$ & 0.253 \\
\hline $\begin{array}{r}\text { Teachers /Civil servants } \\
\text { /Institutions }\end{array}$ & & $0.000(0.000-0.000)$ & 0.996 \\
\hline Famers & & $0.633(0.378-1.060)$ & 0.082 \\
\hline Age $(\geqslant 80)$ & & $3.607(1.308-9.943)$ & 0.013 \\
\hline Age (70 ) & 一。 & $3.386(1.323-8.667)$ & 0.011 \\
\hline $\operatorname{Age}(60 \sim)$ & - & $3.542(1.413-8.879)$ & 0.007 \\
\hline Age ( 50 ) & - & $2.158(0.848-5.494)$ & 0.107 \\
\hline Sleep duration ( $>9 h$ ) & $-\infty$ & $2.107(1.391-3.190)$ & $<0.001$ \\
\hline Sleep duration $(<7 \mathrm{~h})$ & -- & $1.673(0.911-3.071)$ & 0.097 \\
\hline \multicolumn{4}{|c|}{$\begin{array}{rrrr} & 1 & 1 & \\
0.01 .0 & 4.0 & 7.0 & 10.0 \\
\end{array}$} \\
\hline
\end{tabular}

Figure 24 multivariate models for association between sleep duration and the risk of stroke. (A) Model I: sleep duration, gender, and age. (B) Model 2: Model I, educational level, occupation, marital status and migrant workers. (C) Model 3: Model 2, smoking, drinking, and sitting or leaning time every day. (D) Model 4: Model 3, health status, sleep quality, hypertension, diabetes, and coronary heart disease.

an earlier age of stroke, an increased risk of stroke, and thus an increased healthcare burden. Based on that, future studies should focus on sleep duration, stroke pathogenesis, and its molecular epidemiology.

This study has some limitations. It was a cross-sectional survey, preventing any determination of a cause-to-effect relationship. As it was not possible to assess sleep objectively in a sample of this magnitude, sleep duration, stroke history, and other indicators were reported by the participants, resulting in inevitable subjectivity and biases. No blood parameters or intensity, method and type of exercises were analyzed in this study. Furthermore, stroke history and sleep behavior change before baseline were not collected 
in questionnaire. Due to the retrospective nature of the stroke, it is possible that in some of the participants sleep patterns have shifted to the longer sleep duration after the stroke (as in some of them it might have shifted to shorter sleep pattern). Thus, due to the lack of prospective observation, the causal relationship between sleep duration and stroke disease cannot be obtained, and further epidemiological verification is needed.

\section{Conclusions}

In conclusion, a long sleep duration $(>9 \mathrm{~h})$ is independently associated with history of stroke in middle-aged and elderly people in Guiyang. Short sleep duration was not associated with a history of stroke in this population.

\section{Abbreviations}

BMI, body mass index.

\section{Data Sharing Statement}

The datasets used and/or analysed during the current study are available from the corresponding author on reasonable request.

\section{Ethics Approval and Informed Consent}

The study was approved by the ethics committee of Drug Clinical Trial of Affiliated Hospital of Guizhou Medical University and all participants signed the informed consent form.

\section{Acknowledgments}

Thanks to Guiyang Health and Family Planning Commission, Guiyang Center for Disease Control and Prevention, the health and family planning bureau of each investigation district and county, the township health center, the community health service center, the subdistrict office for the organization and coordination of this investigation. Thanks to the investigation site health and family planning professionals, Guizhou Medical University School of Public Health disease spectrum project team to participate in the investigation of teachers and students for the smooth implementation of the investigation paid hard work. Thanks to all the respondents for their support and cooperation.

\section{Author Contributions}

All authors made a significant contribution to the work reported, whether that is in the conception, study design, execution, acquisition of data, analysis and interpretation, or in all these areas; took part in drafting, revising or critically reviewing the article; gave final approval of the version to be published; have agreed on the journal to which the article has been submitted; and agree to be accountable for all aspects of the work.

\section{Funding}

This work was supported by the Project on Investigation of Disease Spectrum of Residents in Guiyang City (BCXZFCG2016-023A). This work was supported by the National Key R\&D Program "Precision Medicine Initiative" of China (Grant no: 2017YFC0907301).

\section{Disclosure}

The authors declare no conflicts of interest in this work.

\section{References}

1. Sacco RL, Kasner SE, Broderick JP, et al. An updated definition of stroke for the 21st century: a statement for healthcare professionals from the American Heart Association/American Stroke Association. Stroke. 2013;44(7):2064-2089. doi:10.1161/STR.0b013e318296aeca

2. Lunardi Baccetto S, Lehmann C. Microcirculatory changes in experimental models of stroke and CNS-injury induced immunodepression. Int J Mol Sci. 2019;20:5184.

3. Donkor ES. Stroke in the 21(st) century: a snapshot of the burden, epidemiology, and quality of life. Stroke Res Treat. 2018;2018:3238165. doi: $10.1155 / 2018 / 3238165$ 
4. Wu S, Wu B, Liu M, et al. Stroke in China: advances and challenges in epidemiology, prevention, and management. Lancet Neurol. 2019;18 (4):394-405. doi:10.1016/S1474-4422(18)30500-3

5. Jiang B, Wang WZ, Chen H, et al. Incidence and trends of stroke and its subtypes in China: results from three large cities. Stroke. 2006;37:63-68. doi:10.1161/01.STR.0000194955.34820.78

6. Hu S, Cui B, Mlynash M, et al. Stroke epidemiology and stroke policies in China from 1980 to 2017: a systematic review and meta-analysis Int J Stroke. 2020;15:18-28. doi:10.1177/1747493019873562

7. Meschia JF, Bushnell C, Boden-Albala B, et al. Guidelines for the primary prevention of stroke: a statement for healthcare professionals from the American Heart Association/American Stroke Association. Stroke. 2014;45:3754-3832. doi:10.1161/STR.0000000000000046

8. Allen CL, Bayraktutan U. Risk factors for ischaemic stroke. Int J Stroke. 2008;3(2):105-116. doi:10.1111/j.1747-4949.2008.00187.x

9. Cabeza de Baca T, Chayama KL, Redline S, et al. Sleep debt: the impact of weekday sleep deprivation on cardiovascular health in older women. Sleep. 2019;42:zsz149.

10. Hermann DM, Bassetti CL. Role of sleep-disordered breathing and sleep-wake disturbances for stroke and stroke recovery. Neurology. 2016;87 (13):1407-1416. doi:10.1212/WNL.0000000000003037

11. Li J, McEvoy RD, Zheng D, et al. Self-reported snoring patterns predict stroke events in high-risk patients with OSA: post hoc analyses of the SAVE Study. Chest. 2020;158(5):2146-2154. doi:10.1016/j.chest.2020.05.615

12. Yaggi HK, Concato J, Kernan WN, et al. Obstructive sleep apnea as a risk factor for stroke and death. $N$ Engl $J$ Med. 2005;353(19):2034-2041. doi:10.1056/NEJMoa043104

13. Cappuccio FP, Cooper D, D'Elia L, et al. Sleep duration predicts cardiovascular outcomes: a systematic review and meta-analysis of prospective studies. Eur Heart J. 2011;32(12):1484-1492. doi:10.1093/eurheartj/ehr007

14. Li W, Wang D, Cao S, et al. Sleep duration and risk of stroke events and stroke mortality: a systematic review and meta-analysis of prospective cohort studies. Int J Cardiol. 2016;223:870-876. doi:10.1016/j.ijcard.2016.08.302

15. Li LJ, Yang Y, Guan BY, et al. Insomnia is associated with increased mortality in patients with first-ever stroke: a 6-year follow-up in a Chinese cohort study. Stroke Vasc Neurol. 2018;3:197-202. doi:10.1136/svn-2017-000136

16. Ji A, Lou H, Lou P, et al. Interactive effect of sleep duration and sleep quality on risk of stroke: an 8-year follow-up study in China. Sci Rep. 2020;10(1):8690. doi:10.1038/s41598-020-65611-y

17. Hirshkowitz M, Whiton K, Albert SM, et al. National Sleep Foundation's sleep time duration recommendations: methodology and results summary. Sleep Health. 2015;1(1):40-43. doi:10.1016/j.sleh.2014.12.010

18. Consultation WE. Appropriate body-mass index for Asian populations and its implications for policy and intervention strategies. Lancet. 2004;363 (9403):157-163. doi:10.1016/S0140-6736(03)15268-3

19. Zhan S. Epidemiology (Seventh Edition, National University Course Book, for Preventive Medical Specialty). Chinese ed. Beijing: People's Medical Publishing House; 2017.

20. Yi X, Luo H, Zhou J, et al. Prevalence of stroke and stroke related risk factors: a population based cross sectional survey in southwestern China. BMC Neurol. 2020;20(1):5. doi:10.1186/s12883-019-1592-z

21. Wang W, Jiang B, Sun H, et al. Prevalence, incidence, and mortality of stroke in China: results from a nationwide population-based survey of 480 687 adults. Circulation. 2017;135(8):759-771. doi:10.1161/CIRCULATIONAHA.116.025250

22. Li XS, HaoYT, LiuMN. Health Statistics. 8th ed. Beijing: People's Medical Publishing House; 2017.

23. Yang JJ, Zhou C, Huang Y, et al. Icotinib versus whole-brain irradiation in patients with EGFR-mutant non-small-cell lung cancer and multiple brain metastases (BRAIN): a multicentre, Phase 3, open-label, parallel, randomised controlled trial. Lancet Respir Med. 2017;5:707-716. doi:10.1016/S2213-2600(17)30262-X

24. Bin YS. Is sleep quality more important than sleep duration for public health? Sleep. 2016;39:1629-1630. doi:10.5665/sleep.6078

25. Patyar S, Patyar RR. Correlation between sleep duration and risk of stroke. J Stroke Cerebrovasc Dis. 2015;24(5):905-911. doi:10.1016/j. jstrokecerebrovasdis.2014.12.038

26. Zhou L, Yu K, Yang L, et al. Sleep duration, midday napping, and sleep quality and incident stroke: the Dongfeng-Tongji cohort. Neurology. 2020;94(4):e345-e356. doi:10.1212/WNL.0000000000008739

27. Patel SR, Zhu X, Storfer-Isser A, et al. Sleep duration and biomarkers of inflammation. Sleep. 2009;32(2):200-204. doi:10.1093/sleep/32.2.200

28. Dowd JB, Goldman N, Weinstein M. Sleep duration, sleep quality, and biomarkers of inflammation in a Taiwanese population. Ann Epidemiol. 2011;21(11):799-806. doi:10.1016/j.annepidem.2011.07.004

29. Su H. Inflammation and genetic factors in stroke pathogenesis. Neuroimmunol Neuroinflamm. 2017;4:260-262. doi:10.20517/2347-8659.2017.22

30. Yang L, Yang H, He M, et al. Longer sleep duration and midday napping are associated with a higher risk of CHD incidence in middle-aged and older Chinese: the Dongfeng-Tongji Cohort Study. Sleep. 2016;39(3):645-652. doi:10.5665/sleep.5544

31. Zhan Y, Chen R, Yu J. Sleep duration and abnormal serum lipids: the China health and nutrition survey. Sleep Med. 2014;15(7):833-839. doi:10.1016/j.sleep.2014.02.006

32. Yang L, Xu Z, He M, et al. Sleep duration and midday napping with 5-year incidence and reversion of metabolic syndrome in middle-aged and older Chinese. Sleep. 2016;39(11):1911-1918. doi:10.5665/sleep.6214

33. Abe T, Aoki T, Yata S, et al. Sleep duration is significantly associated with carotid artery atherosclerosis incidence in a Japanese population. Atherosclerosis. 2011;217(2):509-513. doi:10.1016/j.atherosclerosis.2011.02.029

34. Ramos AR, Dong C, Rundek T, et al. Sleep duration is associated with white matter hyperintensity volume in older adults: the Northern Manhattan Study. J Sleep Res. 2014;23(5):524-530. doi:10.1111/jsr.12177

35. Debette S, Beiser A, DeCarli C, et al. Association of MRI markers of vascular brain injury with incident stroke, mild cognitive impairment, dementia, and mortality: the Framingham Offspring Study. Stroke. 2010;41(4):600-606. doi:10.1161/STROKEAHA.109.570044

36. Lakerveld J, Mackenbach JD, Horvath E, et al. The relation between sleep duration and sedentary behaviours in European adults. Obes Rev. 2016;17(Suppl S1):62-67. doi:10.1111/obr.12381

37. Ford ES, Caspersen CJ. Sedentary behaviour and cardiovascular disease: a review of prospective studies. Int J Epidemiol. 2012;41(5):1338-1353. doi:10.1093/ije/dys078

38. Patel SR, Malhotra A, Gottlieb DJ, et al. Correlates of long sleep duration. Sleep. 2006;29(7):881-889. doi:10.1093/sleep/29.7.881 
39. Pan A, Sun Q, Okereke OI, et al. Depression and risk of stroke morbidity and mortality: a meta-analysis and systematic review. JAMA. 2011;306 (11):1241-1249. doi:10.1001/jama.2011.1282

\section{Publish your work in this journal}

Neuropsychiatric Disease and Treatment is an international, peer-reviewed journal of clinical therapeutics and pharmacology focusing on concise rapid reporting of clinical or pre-clinical studies on a range of neuropsychiatric and neurological disorders. This journal is indexed on PubMed Central, the 'PsycINFO' database and CAS, and is the official journal of The International Neuropsychiatric Association (INA). The manuscript management system is completely online and includes a very quick and fair peer-review system, which is all easy to use. Visit http://www.dovepress.com/testimonials.php to read real quotes from published authors.

Submit your manuscript here: https://www.dovepress.com/neuropsychiatric-disease-and-treatment-journal 